\title{
Convergence of Voter Turnout Rates in U.S. Presidential Elections ${ }^{+}$
}

\author{
Jac C. Heckelman*
}

ABSTRACT. Convergence tests are performed on state-level turnout rates for U.S. presidential elections from 1896 to 2004. The degree of dispersion in turnout has steadily declined since 1940, suggestive of general overall convergence taking place. Individually, it is found that 29 of the 48 continental states are stationary in their relative trend levels, and 42 states either do not significantly differ from the national average or are significantly trending toward the national average. In total, 25 of the 48 states pass tests for both stochastic and $\beta$-convergence, suggesting that national convergence is being achieved by roughly half the states.

Key Words: convergence; stationarity; turnout; presidential elections

JEL Classifications: C22, D72

\section{INTRODUCTION}

Concern has often been expressed regarding the level and trend in turnout for American elections. Turnout levels are lower today than in many other democratic nations, and lower than in the earlier part of America's history. Various explanations have been put forward for the lower levels, ranging from differences in the legal-institutional framework to socio-behavioral changes in a growingly apathetic body of voters. At the same time, there have been a tremendous number of empirical studies seeking the determinants of voter turnout levels (see Mueller [2003] for a recent survey).

In this study, a different question regarding turnout is addressed. Here, I investigate if turnout rates among the U.S. states are converging. Convergence implies there may be a steadystate level of turnout toward which voters are moving. If convergence exists, then turnout levels in states initially below the national average are either increasing by a greater amount or decreasing by a smaller amount relative to states with turnout rates above the national average. Convergence also implies turnout is stationary, at least around a deterministic trend. The notion of convergence has significance for understanding normative issues regarding turnout and its policy implications.

First, some of the concerns regarding fairness of the Electoral College system reflect differences in state turnout rates. Because the number of Electoral College votes assigned to each state is determined by its population and does not depend on how many people vote in the state, voter representativeness in determining the outcome of a presidential election is thought by several political scholars to not be equitable when turnout rates consistently differ across the states (Longley and Pierce, 1999; Haider-Markel et al., 2002; Edwards, 2004). To the extent that

\footnotetext{
${ }^{+}$The author thanks Stephen Knack, Keith Dougherty, Joe McGarrity, Dino Falaschetti, John Dinan, John Moorhouse, Thomas Stratman, and Dennis Coates for their comments and suggestions on an earlier version of this paper, as well as three anonymous referees for this journal.

${ }^{*}$ Heckelman is the Reinsch/Pierce Faculty Fellow and Professor of Economics at Wake Forest University, Winston-Salem, North Carolina. Address: 110 Carswell Hall, Winston-Salem, NC 27109 Email: heckeljc@wfu.edu.
}

(C) Southern Regional Science Association 2010

ISSN 1553-0892

SRSA, 1601 University Avenue, PO Box 6025, Morgantown, West Virginia 26506-6025, USA. 
turnout differences across the states persist, the blocks of voters in a given state are consistently under- or overcounted, as a whole, compared to the total number of voters across the country, in determining the Electoral College outcome. Unlike in a straight popular vote, states have no incentive to increase turnout under the Electoral College (Haider-Market et al., 2002). As noted by Longley and Pierce (1999, p.164), "it is a curious feature of the Electoral College that high turnout in a state is ignored while low levels of voter participation are rewarded." Convergence would imply that such inequities are diminishing over time.

Second, if turnout is nonstationary, then shocks such as the Watergate scandal that turn off voters from the political process (Cebula, 2004, 2005) may result in permanently lower turnout rates as voters do not return in future elections and later generations adopt the apathy of their elders. Similarly, positive shocks that induce greater turnout in a specific election, such as MTV's Rock the Vote campaign to mobilize younger voters (Green and Vavreck, 2008), might permanently raise turnout as energized voters continue to vote and perhaps impress their energy upon the next generation of voters. If turnout is stationary, then one-time shocks will not permanently alter turnout rates.

There are several reasons to believe turnout may be converging. Turnout is defined as the number of actual voters relative to the number of eligible voters. ${ }^{1}$ Over time there has been an increasing degree of federal involvement in the electoral process, especially for national elections, resulting in more of a standardization of practice across the states. This serves to make the numerator and denominator in the turnout estimates more consistently comparable across jurisdictions.

To the extent that various demographic groups do not vote at the same rates, inclusion of these groups for some estimates but not others would lead to differential turnout rates. For example, at the turn of the 20th century women had full suffrage rights in some western states, but not in the rest of the nation until passage of the 19th Amendment in 1920. Historical estimates suggest turnout rates for women differed from those of men (Converse, 1972; Kleppner, 1982), and thus states would have shown differential turnout rates among its age-eligible population even if men voted at the same rate in every state. Similarly, the 26th Amendment (ratified in 1971 to establish the legal age for voting at 18) further standardized the age-eligible population in each state. Because voting rates tend to differ systematically by age (Wolfinger and Rosenstone, 1980; Kleppner, 1982), turnout rates should become less dissimilar once the minimum voting age is the same for every state.

Other federal regulations strictly affected the numerator. The $24^{\text {th }}$ Amendment (ratified in 1964) and the Voting Rights Act of 1965 banned the use of poll taxes and literacy tests, respectively, as prerequisites for voting. Only some states continued to have such voter suppressing requirements in place by the mid-1960s (Ashenfelter and Kelly, 1975; Filer, Kenny, and, Morton, 1991). Still, removal of these barriers to voting would have allowed for more equalization across the states. More recent changes have also taken place. The National Voter Registration Act of 1993 mandated each state to accept mail-in registration and to offer voter registration at motor vehicle bureaus, public libraries, and various state public assistance agencies; it also prohibited the purging of non-voting citizens from the registration rolls. Knack

\footnotetext{
${ }^{1}$ Most academic studies follow the convention of the Statistical Abstracts by using eligibility defined solely by age. McDonald (2002) suggests turnout should instead be measured relative to only the legally eligible citizens. He estimates eligibility by taking into account alien and incarceration rates. However, his data estimates only go back to 1980. Rusk (2001) estimates eligibility based on age, citizenship, race, and gender requirements beginning with the first presidential election in 1789 up through 1996.
} 
(1995) found that motor-voter type provisions already in place in various states before 1993 contributed to higher turnout rates than otherwise would have existed. National legislation should equalize opportunities to take part in elections regardless of the state in which a voter resides.

Variation in electoral laws across the states has been shown to contribute significantly to turnout differences (Ashenfelter and Kelly, 1975; Knack, 1995). Increasing standardization of these laws, therefore, should cause turnout rates to converge. However, there have also been factors working against convergence. Economic variables have also generally been shown to affect turnout (Foster, 1984; Shachar and Nalebuff, 1999). To the degree that states have diverged in their economic fortunes, such variables should reduce the likelihood of convergence in voting rates.

While regional convergence of income is strongly supported (Carlino and Mills, 1993; Loewy and Papell, 1996; Tomljanovich and Vogelsang, 2002), and most states are found to be converging to their regional averages (Carlino and Mills, 1996a; Choi 2004), far fewer states are converging to the national average (Carlino and Mills, 1996b; Choi 2004). ${ }^{2}$ Thus, while most studies suggest income is positively correlated with turnout, the impact of the economy on turnout convergence is uncertain.

In this paper, convergence tests are performed on state-level turnout rates. This involves three parts. First, it is shown that the coefficient of variation is significantly declining over time. Second, most of the states are shown to exhibit $\beta$-convergence, which is consistent with declining variance across the states. Third, stochastic convergence is shown to hold for only a subset of these states. The conclusion is that overall convergence in turnout is occurring for roughly half the states.

\section{BROAD TRENDS IN TURNOUT}

The highest profile elections, which typically generate the largest turnout, are those for the presidency. Official turnout estimates reported in the Statistical Abstracts measure turnout relative to the age-eligible population. Rusk (2001) has recently re-estimated turnout rates for all presidential elections through 1996, as the number of votes cast relative to the number of people eligible to vote, based on criteria for race, age, gender, and citizenship requirements. Given the nature of this study, these turnout data would better reflect differences across states and over time in the proportion of eligible voters who do vote. Election data are therefore taken from this source beginning with the 1896 presidential election, the first election in the post-Reconstruction era, through 1996, the last election for which Rusk calculated turnout rates.

Another common resource used for election data is the series America Votes. Its turnout data have historically been based on the total population that is of voting age. Turnout rates for the 2004 presidential election, however, are listed relative to citizen voting-age population, reflecting the current criteria that Rusk applies (as race and gender requirements are no longer relevant). To bridge the gap, I have also calculated turnout rates for the 2000 election using the total votes cast in each state taken from the Federal Election Commission website, ${ }^{3}$ and the

\footnotetext{
${ }^{2}$ There are a great many cross-sectional studies that find evidence to support income convergence, but Carlino and Mills (1993) criticize these tests. The cross-sectional approach does not make it possible to identify if any particular states do not fit the general pattern of either convergence or divergence characterized by the rest of the states.

${ }^{3}$ See http://www.fec.gov/pubrec/fe2000/2000presge.htm.
}

(C) Southern Regional Science Association 2010. 
number of citizens, 18 years and older, indicated in the 2000 Census. The complete dataset, therefore, includes all presidential elections from 1896 to 2004.

The overall national and unweighted state $^{4}$ average turnout rates for U.S. presidential elections are presented in Figure 1. Both series exhibit virtually identical patterns. Inspecting the graph, there appears to be a structural break occurring after the 1920 election. From 1896 to 1924, the national turnout rate fell fairly steadily from 80 percent to just under 50 percent, with a mean of 63 percent, whereas from 1928 to 2004 turnout fluctuated more readily around an average of 58 percent. Such a change in participation is well documented in the political history literature. For example, Burnham's (1970) theory of the "critical election" of 1896 in which the populist William Jennings Bryan made his famous "Cross of Gold" speech describes a process during the transition of the American economy from agrarian to industrial-capitalism, whereby big business conspired to dominate the electoral process. This destroyed the competitive two-party system at the state level. Without meaningful elections, citizens became more likely to stay home for both state and national elections. Burnham's critics argued that much of the noted drop-off in turnout could have been instigated by various progressive reforms intended to reduce fraudulent voting, such as registration and secret ballots (Rusk, 1974). Dugan and Taggart (1995) contend both effects would have ended in 1920. Rusk (2001, p.42) believes that women only slowly became

\section{FIGURE 1. Turnout Rates in Presidential Elections (in percent)}

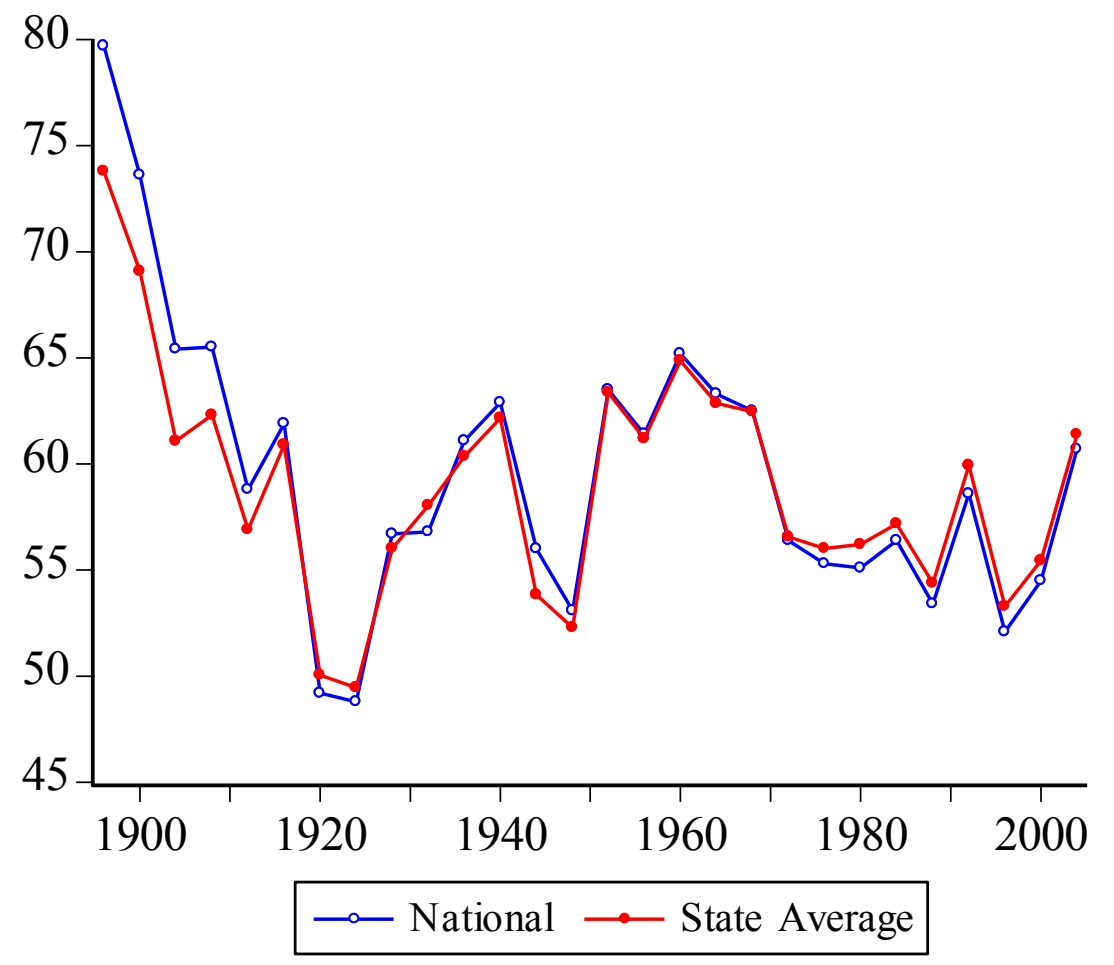

\footnotetext{
${ }^{4}$ Residents in the District of Columbia first began casting Electoral College votes in 1964. Since they are included in the national figures, they are also included in the state average even though DC is not technically a "state."
} 
socialized to vote over time after passage of the 19th Amendment in 1919 and that increased mobilization rates, which started in the 1928 election, are indicative of this phenomenon.

As shown in Figure 1, the average (unweighted) state turnout very closely tracks the national (weighted) turnout rate. In the convergence tests to follow, each state is treated equally. Hence, the focus is on the unweighted average. It is first noted, following from Kenworthy (1999), that convergence should imply a reduction in the variation of turnout across states over time. The coefficient of variation for state turnout rates is plotted for each election in Figure 2. There appears to be a strong downward trend, which is statistically significant $(t=-7.31$ using Newey-West HAC standard errors robust to serial correlation). Similar results hold if the simpler variation in turnout is used instead of the coefficient of variation. This crude test suggests that, as a general rule, convergence is taking place. However, it (or any cross-sectional approach to convergence) fails to identify which, if any, individual states are not converging.

\section{WHICH STATES ARE CONVERGING?}

For the individual state convergence tests, time-series techniques drawing from the unit root and income convergence literature are used. Alaska and Hawaii did not begin casting votes in presidential elections until 1960, and the District of Columbia began in 1964. Hence, individual convergence tests are not conducted for their series, but their turnout rates remain part of the state average. The turnout series for Oklahoma begins in 1908 and for Arizona and New Mexico in 1912. All other states are included back to 1896. Individual state tests for convergence are performed for each of the states within the continental United States.

\section{FIGURE 2. Coefficient of Variation for State Turnout}

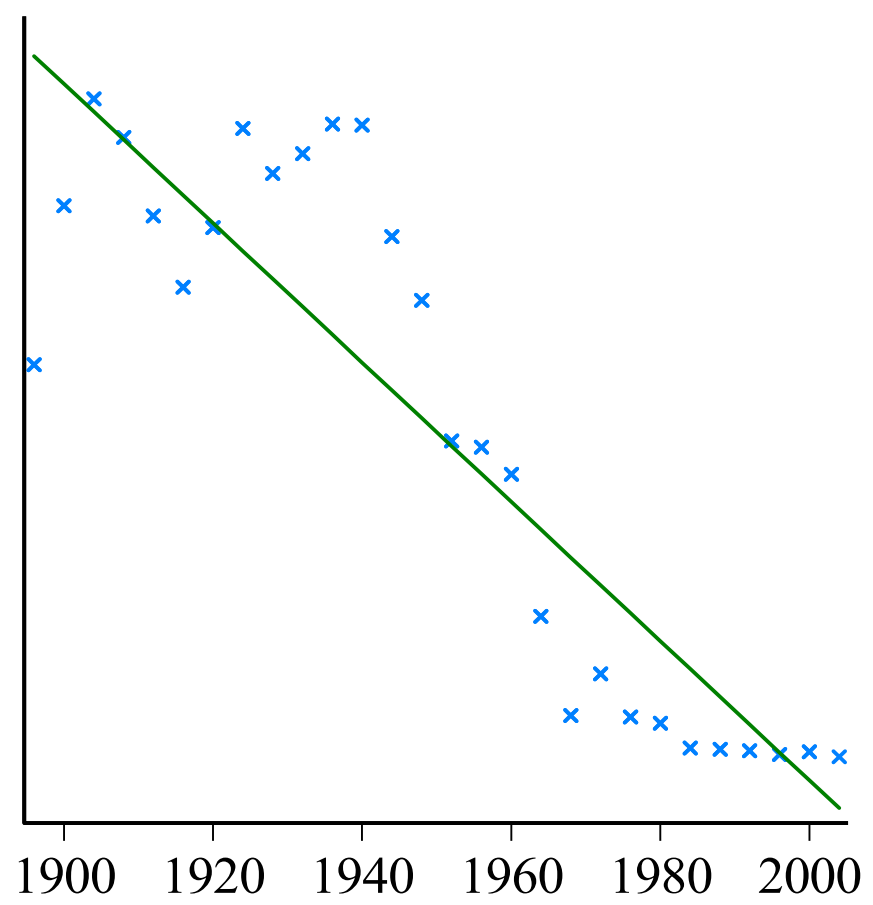


FIGURE 3. Relative Turnout Rates for Selected States

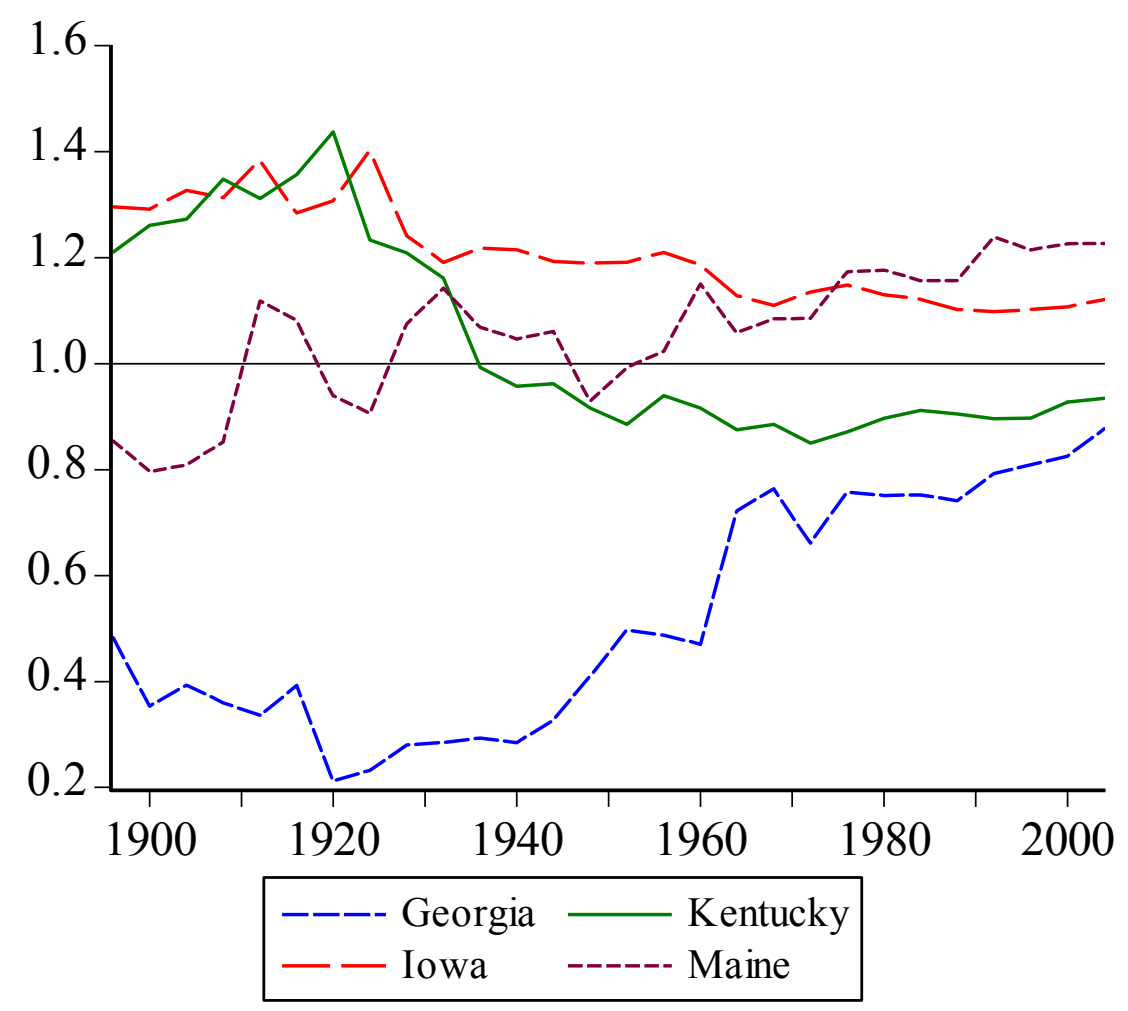

To help visualize, the differing trends for four states are presented in Figure 3. Each series represents a state's relative turnout rate $y_{t}=y_{t}^{*} / \bar{y}_{t}$, where $y_{t}^{*}$ denotes the actual turnout rate in a state and $\bar{y}_{t}$ denotes the average turnout rate for all the states, in the $t^{\text {th }}$ election. According to the graph, Georgia appears to be in the process of reversing its history of relatively low turnout, inching up over time toward the national average, but still currently well below it. Kentucky and Maine appear headed in opposite directions, with Kentucky falling steadily below the national average (approaching Georgia from above) and Maine showing increasingly abovenormal turnout rates. Iowa appears to have consistently above-normal showings at the polls. It remains to be seen whether these trends are stable and significant before convergence can be determined.

As established by Carlino and Mills (1993), convergence requires two conditions. First, stochastic convergence requires that shocks to the relative turnout rate must have only temporary effects. Second, $\beta$-convergence requires that states with initial turnout rates below the average increase their turnout by more than states with initial turnout rates above the average. Both conditions must be met in order to conclude the state exhibits convergence.

\subsection{Stochastic Convergence}

To test for stationarity, consider the relationship

(1) $y_{t}=\mu+\theta t+\alpha y_{t-1}+e_{t}$, 
where $y_{t}$ is the relative turnout rate in the $t^{\text {th }}$ election, $t=\{1, \ldots, T\}, \mu, \theta$, and $\alpha$ are parameters that can be estimated, and $e_{t}$ is a stationary error process. If $\alpha<1$, then a given random shock to the series will have declining impact over time and turnout is considered trend-stationary. However, if $\alpha=1$, then any random shock to turnout will be permanent, indicating that $y_{t}$ has infinite variance, rendering traditional regression estimates meaningless. In this case, the differenced series:

(2) $y_{t}-y_{t-1}=\mu+\theta t+e_{t}$,

is stationary so the original series $y_{t}$ is said to be differenced-stationary. The standard way to test for trend-stationarity versus difference-stationarity in a series is by means of a Dickey-Fuller test. This is performed by transforming (1) into

(3) $y_{t}-y_{t-1}=\mu+\theta t+\rho y_{t-1}+e_{t}$,

where $\rho=\alpha-1$, and testing against the null $\rho=0$. Since the null implies a unit root $(\alpha=1)$, the distribution of the $t$-statistic is nonstandard. Critical values are given in Fuller (1976). Augmented Dickey-Fuller tests include lagged values of the differenced series to accommodate additional serial correlation (the critical values remain the same). For $T=25$, critical values are -3.24 at 10 percent error allowance and -3.60 for 5 percent error allowance. Because $\alpha>1$ is always ruled out by assumption (otherwise the series would be "exploding"), unit root tests are one-tailed. Thus, a Dickey-Fuller test statistic less than the critical value (which is negative) indicates rejecting the null of non-stationarity.

Stochastic convergence of relative turnout is first identified by the standard Dickey-Fuller tests for stationarity. The number of lags is determined by the "testing-down" method of dropping the last lag if it is not significant, re-estimating the equation without it, and continuing the process until the last lag used is significant or no lags are left. ${ }^{5}$ The presence of a unit root is rejected for 22 states at the 5 percent level, and one additional state (New York) at the 10 percent level, as indicated in the second column of Table $1 .^{6}$

Alternatively, Perron (1989) has demonstrated that Dickey-Fuller tests have low power for rejecting a unit root in the presence of a single structural break in the trend function of the series. He showed various macroeconomic series may be considered stationary after allowing for a break in the level and/or rate of change of the trend. Perron developed alternative stationarity tests to account for structural breaks. Again, the distribution of the $t$-statistic for the estimated coefficient on the lagged dependent variable is nonstandard under the null $\alpha=1$, and depends on the specific breakpoint. ${ }^{7}$ There remains the possibility that other states are also converging but are stationary around a single break that the Dickey-Fuller tests may fail to capture. Judging from Figure 1, there appears to be evidence of a break in both the level and rate of change for national (or average) turnout around 1920, but this does not necessarily correspond to the relative turnout series for any given state.

\footnotetext{
${ }^{5}$ Due to the small sample size, a maximum of two lags was considered.

${ }^{6}$ Elliot, Rothenberg, and Stock (1996) proposed a method for detrending the data first. Detrending can increase the power of standard unit-root tests. Test statistics generated by generalized least squares suggest that only one of the states (Virginia) which did not previously reject the null of non-stationarity would now be considered stationary. Note, however, that the same conclusion for this state is reached using the Zivot-Andrews endogenous break-point routine discussed below, where additional states are also found to be stationary. Results for all states using the ADF-GLS procedure are available upon request.

${ }^{7}$ Perron (1989) presents critical values for a range of potential breakpoints, based on the proportion of observations up to the break point.
}

(C) Southern Regional Science Association 2010. 
TABLE 1. Stochastic Convergence Tests of Voter Turnout by State

\begin{tabular}{|c|c|c|c|c|}
\hline State & Lags & $\begin{array}{l}\text { Dickey-Fuller } \\
t \text {-statistic }\end{array}$ & $\begin{array}{l}\text { Zivot-Andrews } \\
t \text {-statistic }\end{array}$ & Break year \\
\hline Alabama & 0 & -3.10 & -3.32 & 1964 \\
\hline Arizona & 2 & $-4.67 * *$ & --- & --- \\
\hline Arkansas & 0 & -2.05 & -3.13 & 1920 \\
\hline California & 0 & -1.68 & -3.67 & 1940 \\
\hline Colorado & 0 & -2.61 & $-5.25 * *$ & 1920 \\
\hline Connecticut & 0 & -2.97 & $-5.25 * *$ & 1944 \\
\hline Delaware & 0 & $-4.55 * *$ & --- & --- \\
\hline Florida & 0 & $-5.03 * *$ & --- & --- \\
\hline Georgia & 0 & -2.89 & -4.39 & 1920 \\
\hline Idaho & 1 & -1.09 & -3.63 & 1920 \\
\hline Illinois & 0 & -2.42 & -4.38 & 1924 \\
\hline Indiana & 2 & $-3.76 * *$ & --- & --- \\
\hline Iowa & 0 & $-3.73 * *$ & --- & --- \\
\hline Kansas & 2 & $-4.66 * *$ & --- & --- \\
\hline Kentucky & 0 & -1.31 & -3.79 & 1924 \\
\hline Louisiana & 0 & $-3.76 * *$ & --- & --- \\
\hline Maine & 1 & $-4.42 * *$ & --- & --- \\
\hline Maryland & 1 & -1.27 & -4.36 & 1924 \\
\hline Massachusetts & 1 & -2.01 & $-4.97^{*}$ & 1928 \\
\hline Michigan & 0 & -2.42 & -4.78 & 1940 \\
\hline Minnesota & 1 & $-4.04 * *$ & --- & --- \\
\hline Mississippi & 0 & -1.95 & -4.09 & 1968 \\
\hline Missouri & 0 & -2.25 & -2.70 & 1964 \\
\hline Montana & 0 & -2.56 & -4.34 & 1916 \\
\hline Nebraska & 0 & $-4.72 * *$ & --- & --- \\
\hline Nevada & 1 & -2.98 & -3.75 & 1908 \\
\hline New Hampshire & 0 & $-3.81 * *$ & --- & --- \\
\hline New Jersey & 1 & $-4.36 * *$ & --- & --- \\
\hline New Mexico & 0 & $-4.67 * *$ & --- & --- \\
\hline New York & 0 & $-3.45^{*}$ & --- & --- \\
\hline North Carolina & 0 & $-4.32 * *$ & --- & --- \\
\hline North Dakota & 0 & $-4.13 * *$ & --- & --- \\
\hline Ohio & 0 & -1.93 & -3.62 & 1976 \\
\hline Oklahoma & 0 & $-3.70 * *$ & --- & --- \\
\hline Oregon & 2 & $-3.94 * *$ & --- & --- \\
\hline Pennsylvania & 0 & $-3.84 * *$ & --- & --- \\
\hline Rhode Island & 2 & -2.67 & $-5.72 * *$ & 1924 \\
\hline South Carolina & 0 & -2.27 & -3.58 & 1952 \\
\hline South Dakota & 0 & $-4.85 * *$ & --- & --- \\
\hline Tennessee & 0 & -2.50 & -4.36 & 1924 \\
\hline Texas & 0 & $-6.07 * *$ & --- & --- \\
\hline Utah & 2 & -0.69 & -3.35 & 1948 \\
\hline Vermont & 0 & $-4.11 * *$ & --- & --- \\
\hline Virginia & 0 & -3.02 & $-5.09 * *$ & 1912 \\
\hline Washington & 0 & -1.99 & -4.06 & 1940 \\
\hline West Virginia & 0 & $-3.65 * *$ & --- & --- \\
\hline Wisconsin & 0 & -2.90 & -4.51 & 1916 \\
\hline Wyoming & 0 & -2.29 & $-6.55^{* *}$ & 1924 \\
\hline
\end{tabular}

(C) Southern Regional Science Association 2010. 
Zivot and Andrews (1992), among others, note that the distribution used to determine Perron's critical values is not valid when the break points are selected by observing the data. Indeed, for turnout there are many potential landmark shocks that could fundamentally alter the series, such as the Great Depression, the 1965 Voting Rights Act, Watergate, etc. Choosing a date based on the observed data involves pre-test bias. Zivot and Andrews therefore claim Perron's critical values are too small (in absolute value) and therefore too easy to reject a unit root. As there is no date that one can predict at which each state is likely to break relative to the other states, ${ }^{8}$ the endogenous break routine developed by Zivot and Andrews is utilized on the remaining states for which a unit root was not initially rejected.

Zivot and Andrews propose that instead of pre-selecting a break point, it is necessary to conduct an exhaustive search over all possible breakpoints. With an unknown breakpoint, the unit-root test under the null of a random walk with drift becomes:

(4) $y_{t}=\mu+\theta t+\lambda$ post $x_{t}+\gamma\left(t^{*}\right.$ postx $\left._{t}\right)+\alpha y_{t-1}+e_{t}$

where $\operatorname{post}_{t}=1$ for all elections after year $x$ and 0 for all elections up to and including $x$, for all potential values of $x$. They suggest identifying the breakpoint by the choice of $x$ from the $T-2$ regressions that minimizes the $t$-statistic for $\alpha=1$ and, therefore, is least favorable toward the null. Since the breakpoint itself is now being estimated, Perron's critical values cannot be used. Zivot and Andrews derive the asymptotic critical values under their estimation routine: -4.82 for 10 percent error allowance and -5.08 for 5 percent error allowance. Again, a test statistic less than the critical value suggests rejecting the null of non-stationarity. Test results, along with the endogenously determined break year, are given in the last two columns of Table 1, for the 25 states that the Dickey-Fuller tests do not already identify as stationary.

The modal break year is 1924 , which roughly corresponds to the apparent break date for national turnout. Indeed, almost half of the states (12 of 25) are estimated to have their break point within one election of the 1920 election. The earliest estimated break is for Nevada in 1908, and the latest in 1976 for Ohio, the only state estimated to have had a break in the postWatergate era. Neither of these latter states are found to be stationary under the Zivot-Andrews test when allowing for a break in the series.

It is found that a unit root can be rejected at the 5 percent level, however, for five additional states once a break in the series is allowed, and also for another state (Massachusetts) at the 10 percent level. Thus, the conclusion is that in total 29 of the 48 continental states are stochastically converging in turnout. For the rest, there does not seem to be a tendency to maintain a stable trend level of turnout relative to other states. Thus, the impact from one-time electoral changes in those states tends to persist well into the future.

\section{2 $\beta$-Convergence}

Next, tests for $\beta$-convergence are performed. Any of the stochastically convergent states that also support $\beta$-convergence would then be classified as converging in turnout to the national average. Time series tests for $\beta$-convergence with an unknown break point are developed in Vogelsang (2001) and Tomljanovich and Vogelsang (2002). Consider the regression:

\footnotetext{
${ }^{8}$ For example, the impact of civil rights legislation, such as the 1965 Voting Rights Act, may have had a bigger impact in the South than the rest of the nation. The timing of other important state and local electoral reforms, such as the date at which secret ballots and registration were introduced, varied across states.
}

(C) Southern Regional Science Association 2010. 
(5)

$$
y_{t}=\mu_{1}\left(1-\text { postx }_{t}\right)+\delta_{1}\left(t *\left(1-\text { postx }_{t}\right)\right)+\mu_{2} \text { post }_{t}+\delta_{2}\left(\left(t-n_{x}\right) * \text { postx }_{t}\right)+\omega_{t} \text {, }
$$

where $y_{t}$ again represents the relative turnout in the the election, $\mathrm{nx}$ is the value of $\mathrm{t}$ (observation number) for an election in year $\mathrm{x}, \omega_{t}$ is zero mean error term that may be serially correlated, and the other variables are defined as prior. The parameter $\mu_{1}$ would determine if relative turnout is above $\left(\mu_{1}>1\right)$ or below $\left(\mu_{1}<1\right)$ the average at the start of the series whereas $\delta 1$ represents the rate of change until the break year. ${ }^{9}$ Likewise, $\mu_{2}$ would determine if relative turnout is above or below the average in the estimated break year, and $\delta_{2}$ represents the rate of change after the break year. The criteria for convergence is based on the $t$-statistics for the nulls of $\mu_{i}=1$ and $\delta_{i}=0$ being of opposite sign, for $i=1$ before the break year, or $i=2$ after the break year. This would imply that states with turnout rates initially above the norm declined or that those with turnout rates initially below the norm increased toward the average. If neither $t$-statistic exceeds (in absolute value) the critical value, this implies the state was initially at the mean value for all the states, did not significantly trend away, and has therefore fully converged. Otherwise, if the state began at the average and significantly trended away, or began with a turnout rate exceeding (below) the national average that did not signifcantly fall (increase) relative to the average change to a statistically significant extent, the state is interpreted to be $\beta$ divergent. ${ }^{10}$

The estimation process is as follows from Vogelsang (2001). First, the break year is estimated by choosing the election which maximizes the normalized Wald statistic for no break (i.e., $\mu_{1}=\mu_{2}, \delta_{1}=\delta_{2}$ ). Trimming is performed to limit the potential break years to be excluded from the first and last 10 percent of the sample election years. The normalized $t$-statistics ${ }^{11}$ for the nulls of $\mu_{i}=1$ and $\delta_{i}=0$ are presented in Table 2 for each state. The critical values presented by Vogelsang (2001) appear at the bottom of the table.

The breaks again are largely clustered near 1920, with roughly 40 percent of all states having their break occur within the 1920s, although two distinct groups of nine states also have their breaks estimated to be 1912 or 1952. Based on the signs and significance of the $t$-statistics, only 19 states were $\beta$-converging or had already $\beta$-converged prior to their breaks, and only six states were not converging after their break years. ${ }^{12}$ Furthermore, 18 states were $\beta$-converging both before and after their breaks. Overall, turnout rates across the states are becoming more similar than used to be the case, although there are still a few (six) holdouts. This is consistent with the declining coefficient of variation shown earlier.

For example, Alabama, Arizona, and Arkansas had initial turnout rates significantly below average, but after their respective breaks, they fully converged. California and Colorado had fully $\beta$-converged before and after their breaks. Connecticut's turnout rate remains significantly above the average. Delaware initially had a turnout rate below the national average, but after its break year of 1912 had a turnout rate significantly above average. Since then it has

\footnotetext{
${ }^{9}$ Tomljanovich and Vogelsang (2002) used the $\log$ of relative income as their dependent variable, so their interest in $\mu_{1}$ and $\mu_{2}$ focused on whether these parameters were above or below zero.

${ }^{10}$ Note this is a more strenuous criterion for $\beta$-convergence than suggested by Tomljanovich and Vogelsang (2002). They interpret support for $\beta$-convergence to occur if the $t$-statistics are of opposite sign, even if only one of them is statistically significant. (If neither is statistically significant, then $\beta$-convergence has already occurred.) Divergence would be supported only by $t$-statistics which are of the same sign, with at least one them being statistically significant.

${ }^{11}$ Estimated $t$-statistics are divided by the square root of the sample size.

${ }^{12}$ States that are interpreted to have $\beta$-converged or be $\beta$-converging post-break are marked with "\#” in Table 2.
} 
TABLE 2. $\beta$-Convergence $t$-Statistics of Voter Turnout by State

\begin{tabular}{|c|c|c|c|c|c|}
\hline State & $\mu_{1}$ & $\gamma_{1}$ & $\mu_{2}$ & $\gamma_{2}$ & break year \\
\hline Alabama\# & $-1.69 * *$ & -0.78 & -2.08 & 1.32 & 1952 \\
\hline Arizona\# & $-0.96 * *$ & 0.76 & -1.85 & 0.36 & 1924 \\
\hline Arkansas\# & $-1.21 * *$ & -0.93 & -1.24 & 0.66 & 1952 \\
\hline California\# & -0.38 & 0.26 & 1.20 & -0.91 & 1940 \\
\hline Colorado\# & 0.07 & 0.17 & 2.26 & -1.32 & 1924 \\
\hline Connecticut & $1.31 * *$ & 0.23 & $2.72 *$ & -1.38 & 1944 \\
\hline Delaware\# & $-0.98 * *$ & 0.98 & $4.50 * *$ & $-3.14 * *$ & 1912 \\
\hline Florida & $-2.73 * *$ & 0.24 & -2.21 & $1.49 *$ & 1940 \\
\hline Georgia\# & $-1.82 * *$ & -0.19 & $-5.74 * *$ & $3.09 * *$ & 1920 \\
\hline Idaho & 0.15 & 0.13 & $2.49 *$ & -1.11 & 1920 \\
\hline Illinois\# & $1.90 * *$ & 0.26 & 1.63 & -1.05 & 1952 \\
\hline Indiana\# & $1.28 * *$ & 0.92 & $7.19 * *$ & $-5.24 * *$ & 1912 \\
\hline Iowa & $2.56 * *$ & 0.41 & $3.49 * *$ & -1.29 & 1928 \\
\hline Kansas\# & $1.55 * *$ & -0.20 & 0.59 & -0.29 & 1952 \\
\hline Kentucky\# & $1.46^{* *}$ & -0.13 & -0.41 & -0.20 & 1936 \\
\hline Louisiana\# & $-2.07 * *$ & -0.30 & $-3.95 * *$ & $2.82 * *$ & 1928 \\
\hline Maine\# & -0.40 & 0.01 & -0.13 & 0.89 & 1912 \\
\hline Maryland\# & $1.13 * *$ & -0.49 & -1.11 & 0.42 & 1924 \\
\hline Massachusetts\# & $-0.89 * *$ & $2.28 * *$ & 1.82 & -0.91 & 1952 \\
\hline Michigan\# & $2.67 * *$ & $-1.62 *$ & 1.17 & -0.45 & 1940 \\
\hline Minnesota\# & $0.76^{* *}$ & -0.35 & 1.78 & 0.52 & 1920 \\
\hline Mississippi\# & $-4.90 * *$ & 0.62 & -0.61 & 0.10 & 1968 \\
\hline Missouri\# & $0.92 * *$ & 0.75 & $2.83^{*}$ & $-1.82 *$ & 1924 \\
\hline Montana\# & 0.17 & -0.03 & 1.70 & -0.25 & 1916 \\
\hline Nebraska\# & 0.11 & 0.54 & 2.19 & -1.41 & 1912 \\
\hline Nevada\# & 0.08 & 0.46 & 0.15 & -0.61 & 1952 \\
\hline New Hampshire & 0.04 & 0.51 & $2.62 *$ & -1.41 & 1912 \\
\hline New Jersey\# & $1.50 * *$ & -0.22 & $2.65 *$ & $-1.67^{*}$ & 1928 \\
\hline New Mexico\# & -0.35 & 0.53 & 0.50 & -0.72 & 1928 \\
\hline New York\# & $1.23 * *$ & -0.03 & 0.63 & -0.62 & 1952 \\
\hline North Carolina\# & 0.59 & -0.80 & -1.68 & 0.40 & 1912 \\
\hline North Dakota\# & 0.09 & 0.40 & 2.23 & -0.99 & 1920 \\
\hline Ohio\# & $3.63 * *$ & $-2.00 * *$ & -0.06 & 0.24 & 1976 \\
\hline Oklahoma\# & 0.48 & -0.65 & 0.27 & -0.53 & 1940 \\
\hline Oregon\# & $0.93 * *$ & -1.25 & 0.38 & 0.97 & 1912 \\
\hline Pennsylvania\# & $0.79 *$ & -0.63 & 0.80 & -0.73 & 1936 \\
\hline Rhode Island\# & $-1.29 * *$ & 1.46 & $3.40 * *$ & $-2.17 * *$ & 1924 \\
\hline South Carolina & $-3.79 * *$ & -0.53 & $-3.01 * *$ & 1.42 & 1952 \\
\hline South Dakota\# & $1.30 * *$ & -0.33 & 2.18 & -0.86 & 1928 \\
\hline Tennessee\# & -0.26 & -0.49 & $-3.67 * *$ & $2.13 * *$ & 1924 \\
\hline Texas\# & 0.63 & -1.16 & $-3.22 * *$ & $1.71 *$ & 1912 \\
\hline Utah\# & $0.77 *$ & 1.01 & 2.15 & -1.37 & 1952 \\
\hline Vermont\# & -0.16 & -1.02 & $-3.49 * *$ & $2.20 * *$ & 1924 \\
\hline Virginia\# & -0.25 & -0.12 & 0.46 & 0.23 & 1912 \\
\hline
\end{tabular}

(C) Southern Regional Science Association 2010. 
TABLE 2: $\beta$-Convergence $\boldsymbol{t}$-Statistics of Voter Turnout by State (Continued)

\begin{tabular}{lcclll}
\hline Washington\# & $-1.10^{* *}$ & 1.15 & 1.54 & -0.77 & 1944 \\
West Virginia\# & $1.48^{* *}$ & 0.65 & $3.89 * *$ & $-3.34 * *$ & 1928 \\
Wisconsin\# & $1.92^{* *}$ & -0.89 & 1.32 & 0.16 & 1924 \\
Wyoming\# & $-1.33^{* *}$ & 0.88 & 1.81 & -1.04 & 1924 \\
\hline critical value 5\% & \pm 0.88 & \pm 2.00 & \pm 3.00 & \pm 2.01 & \\
critical value 10\% & \pm 0.67 & \pm 1.47 & \pm 2.37 & \pm 1.48 & \\
\hline \hline
\end{tabular}

Notes: * indicates significance at the 10 percent level; ** indicates significance at the 5 percent level; \# indiciates state is $\beta$-Converging (or converged) post-break; States in bold are stochastically converging (see Table 1) and $\beta$-Converging (or converged) post-break.

shown a declining trend toward the national average and is therefore now in the process of $\beta$ converging. Georgia was not $\beta$-converging prior to its break in 1920 , but currently is. The other states can be interpreted similarly. Only Connecticut, Florida, Idaho, Iowa, New Hampshire, and South Carolina are considered to be $\beta$-diverging after their break years. These states are geographically dispersed across the nation; all except the two southern states are estimated to be remaining above the national average.

\subsection{Summarizing the Convergence Tests}

Recall that convergence requires both stochastic convergence and $\beta$-convergence. Each of the 29 states which are stochastically converging, except for Connecticut, Florida, Iowa, and New Hampshire, are also $\beta$-converging or already $\beta$-converged in their post-break elections. Thus the conclusion is that 25 states are currently converging in turnout. Put another way, even though 42 of the continental states are found to be $\beta$-converging, the lack of stationarity for several of these series prevents concluding that many of them are actually converging in the full sense. The 25 states that are both stochastically and $\beta$-converging are in boldface font in Table 2 . Thus, slightly more than half the states are fully converging in turnout.

Consider, for example, the implications for Iowa and Indiana. Both states are found to be stochastically convergent and had above-average turnout after their break years. Because the number of Electoral College votes assigned to each state is determined by Census population and does not depend on how many people vote in the state, above-average turnout implies that the blocks of voters in these states were under-counted as a whole, compared to the total number of voters across the country, in determining the Electoral College outcome (Longley and Pierce, 1999, Edwards, 2004). Note, however, that Indiana was found to be $\beta$-converging while Iowa was not. This suggests that over time the degree of under-counting Indiana voters (as opposed to residents) has declined, whereas it has not for Iowa voters. The next section investigates factors that might help to explain which states are converging and which are diverging.

\section{DETERMINANTS OF CONVERGENCE}

A variety of factors have been used in the empirical literature to explain variation in turnout levels for a specific election or for several elections pooled together. In contrast, what is of interest here are stable factors that might influence long term relative trends in voting levels, rather than trying to explain the cross-sectional variation in turnout itself. In general, factors that influence turnout levels but are unique to only a few states should, ceteris paribus, result in these states having distinctively different turnout levels than the other, more typical, states. Thus they 
are less likely to be convergent in turnout. Similarly, turnout factors that are becoming increasingly similar among the majority of states should contribute to those states converging in turnout.

Several empirical studies have reported the presence of heteroskedastic errors in turnout regressions, and as a result, observations are often weighted as a function of population size to control for this (Filer, Kenny, and, Morton, 1991; Knack, 1995). Under these models, variance of the turnout residuals is proportional to the population size. The expectation, then, is that larger states are less likely to be converging. Although state population size is not fixed, relative changes are limited in scope.

Turnout in presidential elections also tends to increase when there is a concurrent gubernatorial election (Kau and Rubin, 1976; Filer, Kenny, and, Morton, 1991; Knack, 1995; Shachar and Nalebuff, 1999). Only 11 states currently hold their gubernatorial elections in presidential election years. ${ }^{13}$ Holding constant other relevant factors, these 11 states should consistently have turnout rates greater than the average of all the states, and therefore be less likely to converge.

Past research has also identified a few socio-economic determinants of turnout. For example, a significantly positive relationship has been found between state turnout rates in presidential elections and the state's per capita income (Crain and Deaton, 1977; Foster, 1984; Shachar and Nalebuff, 1999). Because the states at either extreme (very high or very low) would be quite different from the typical states and, therefore, less likely to converge in turnout, the current income level should not predict convergence/divergence. However, to the extent that states are becoming more similar in their incomes over time, those states converging in income should become more similar in turnout as well. In other words, states that are converging in income are becoming more similar to the other states in this important determinant of voter turnout. For example, consider two states, A and B, which currently have equally low incomes. Suppose that in the past, state A was very poor but over time has grown in income more rapidly than has the national average, whereas state B, which had been relatively wealthier than state A (although it, too, still has an income level below average) has grown much more slowly. Thus state A's income caught up to state B's. State A's convergence in income would suggest that it is more likely to be converging in voter turnout (even if not yet fully converged) than state B, whose divergence in income would suggest it is more likely to be diverging in turnout.

Probit regressions are used to test for the factors that determine turnout convergence. For each state the dependent variable is assigned a value of 1 if it is converging in turnout (identified by the bold state names in Table 3 ), and 0 if it is not. The independent variables are the log of the citizen voting age population in 2000 , a binary indicator variable identifying the states that currently hold gubernatorial elections coinciding with presidential elections, and a binary variable identifying the states that are converging in income. ${ }^{14}$

\footnotetext{
${ }^{13}$ See the National Governors Association website: www.nga.org.

${ }^{14}$ The income convergence variable is based on Carlino and Mills's (1996b) summary list given in their Table 4. More recently Choi (2004) identifies ten states that are stochastically converging in income from 1947 to 2001 . All ten states are found here to converge in turnout as well. However, Choi does not determine if any of the states also exhibit evidence of $\beta$-convergence for income. Thus, he only considers stationarity of each state's relative income series and does not determine which, if any, of these states are also becoming more similar in their income levels over time. Other studies (e.g. Carlino and Mills, 1996a) test for state convergence to their regional averages. Because the regions have not yet fully converged (Loewy and Papell, 1996; Tomljanovich and Vogelsang, 2002), this is not the same as converging to the national average.
} 
Probit estimates are reported in the first column of Table 3. While each variable has the expected estimated coefficient sign, only the population variable is statistically significant, just barely meeting the standard 10 percent threshold. It does appear, at least initially, that larger states are less likely to be converging in turnout. However, whether or not a state holds concurrent gubernatorial elections or is converging in income does not significantly affect its likelihood to be converging in turnout.

A final factor to consider is geography. Regional dummies, particularly for the South, are often employed as control variables in turnout regressions (Foster, 1984; Shachar and Nalebuff, 1999). Regional divergence in voter attitudes and party preferences is well documented (Key, 1949; Shaffer, 1981; McKee, 2008). Based on their analysis of survey responses, Glaeser and Ward (2006, p. 132) conclude that "[w]hile the geographic differences within America are large, they are not new and do not seem to be growing." In terms of turnout, southern states in particular are thought to consistently have voter participation rates below the norm (Shaffer, 1981; Foster, 1984). Persistently lower rates of turnout truly should suggest non-convergence.

The Inter-University Consortium for Political and Social Research (ICPSR) groups states into four regions based on historical partisan voting patterns. They are identical to the four Census regional classifications of Northeast, South, Midwest, and West, except ICPSR places Delaware in the Northeast region instead of the South. Probit estimates from a regression including ICPSR regional dummies for the latter three categories, treating the Northeast as the default region, are presented in the middle column of Table 3. Controlling for region eliminates the tenuous significance of the population variable. The only statistically significant variable is the dummy for the South. The negative coefficient indicates southern states are less likely to be converging to the national average. This suggests that the low turnout rates in the South remain persistent and are not significantly improving. Results using Census classifications are similar except the coefficient of the South dummy is smaller. As shown in Table 2, Delaware is found to be converging in turnout. Thus, the Census classification of Delaware as southern reduces both the share of northeastern states converging and the share of southern states diverging. Thus the South appears to be a little less dissimilar to the Northeast.

A further breakdown is possible into subregions. This is important if there are remaining intraregional differences. For example, within the Northeast, all states comprising the MidAtlantic subregion (New York, New Jersey, Pennsylvania, and also Delaware for ICPSR) are converging, whereas two New England states (Connecticut and New Hampshire) are not. Except for the South, which has three, each region comprises two subregions. The Southeast subregion under the Census definition contains only four states, none of which are converging in turnout.

The ICPSR, however, classifies two of them (Kentucky and Tennessee) as "Border South" along with three other states. The other two Census Southeast states (Alabama and Mississippi) are labeled "Solid South" along with the remaining eight other South states. The remaining subregions - East North Central, West North Central, Mountain, and Pacific - are identical under both the ICPSR and Census definitions. The last column of Table 3 replaces the ICPSR regional dummies with their separate subregion dummies. Because all states in the Mid-Atlantic have the same value (one) for the dependent variable, however, this subregion dummy is a perfect predictor of turnout convergence and so it must be excluded from the probit regression. Therefore, the Northeast is not broken out, and all subregional dummies are interpreted as relative to the Northeast. 
TABLE 3. Probit Estimates for Probability of State Converging in Turnout ( $t$-statistics)

\begin{tabular}{|c|c|c|c|}
\hline & Base & $\begin{array}{l}\text { Region } \\
\text { dummies }\end{array}$ & $\begin{array}{c}\text { Subregion } \\
\text { dummies }\end{array}$ \\
\hline \multirow[t]{2}{*}{ Constant } & 4.87 & 5.09 & 3.00 \\
\hline & $(1.55)$ & $(1.51)$ & $(0.73)$ \\
\hline \multirow{2}{*}{ Voting population } & $-0.80 *$ & -0.72 & -0.37 \\
\hline & $(-1.61)$ & $(-1.37)$ & $(-0.58)$ \\
\hline \multirow{2}{*}{ Governor election } & -0.09 & -0.13 & -0.08 \\
\hline & $(-0.19)$ & $(-0.28)$ & $(-0.17)$ \\
\hline \multirow[t]{2}{*}{ Income convergence } & 0.45 & 0.55 & 0.34 \\
\hline & $(0.96)$ & $(1.07)$ & $(0.62)$ \\
\hline South & --- & $\begin{array}{c}-1.08 * \\
(-1.84)\end{array}$ & --- \\
\hline Border South & --- & --- & $\begin{array}{r}-1.11 \\
(-1.50)\end{array}$ \\
\hline Solid South & --- & --- & $\begin{array}{l}-1.09 * \\
(-1.69)\end{array}$ \\
\hline Midwest & --- & $\begin{array}{r}-0.86 \\
(-1.42)\end{array}$ & --- \\
\hline East North Central & --- & --- & $\begin{array}{l}-1.51 * \\
(-1.79)\end{array}$ \\
\hline West North Central & --- & --- & $\begin{array}{r}-0.42 \\
(-0.59)\end{array}$ \\
\hline West & --- & $\begin{array}{r}-0.93 \\
(-1.55)\end{array}$ & --- \\
\hline Mountain & --- & --- & $\begin{array}{r}-0.87 \\
(-1.33)\end{array}$ \\
\hline Pacific & --- & --- & $\begin{array}{r}-1.09 \\
(-1.20)\end{array}$ \\
\hline Pseudo $R^{2}$ & 0.05 & 0.11 & 0.13 \\
\hline log likelihood & -31.72 & -29.67 & -28.96 \\
\hline LR statistic & 3.02 & 7.13 & 8.54 \\
\hline
\end{tabular}

The five East North Central states (Illinois, Indiana, Michigan, Ohio, and Wisconsin) are estimated to be significantly less likely to converge in turnout relative to the states of the Northeast. This result was obscured when the East North Central is lumped in with the other seven Midwestern states. In addition, it is found that likelihoods of states in the South converging in turnout differs within that region. In particular, the effect is significant for the 
Solid South, but not the Border South. The non-geographic variables remain statistically insignificant, with $t$-statistics declining when subregion is controlled. In fact, a Wald test is unable to reject even joint significance of these variables. ${ }^{15}$ Other than geographic location of a state, none of the proposed variables is useful in determining turnout convergence.

\section{CONCLUSIONS}

Time-series tests suggest that 25 of the 48 continental states are converging in turnout. These states pass tests for both stochastic convergence and $\beta$-convergence. All states except six are currently $\beta$-converging or have already fully $\beta$-converged, which suggests turnout rates are generally becoming more similar. Due to the lack of stochastic convergence, the trends are not stable. Overall, 23 states appear to be diverging in turnout.

Because the number of electoral college votes assigned to a state does not depend on how many potential voters actually cast ballots, several political scholars have been critical of the Electoral College system for perpetuating differences across states in each voter's contribution to the value of an Electoral College vote, and thus to the final electoral outcome (Longley and Pierce, 1999; Haider-Markel et al., 2002; Edwards, 2004). The findings here regarding nonconvergence among so many states suggest that inequities in Electoral College representation persist.

Several variables were considered to be predictors of whether states are converging or diverging. None were found to be statistically significant. There is some evidence, however, that geographic location plays a role. Relative to the Northeast states, the states of the South (and in particular the Deep South) and East North Central regions are less likely to be converging in turnout. Future work can investigate this relationship further. For example, even though the Solid South tends not to be converging to the national average for turnout, it may be converging toward the average for the overall South. This form of "club" convergence where states that share similar characteristics, such as political cleavages or socio-economic variables, might be converging amongst themselves may also be occurring in other regions. Alternative techniques could also be used to investigate if non-stationary turnout series within a given region are cointegrated. Finally, given that income is a strong determinant of turnout (Foster, 1984; Shachar and Nalebuff, 1999), income convergence may better reflect on different patterns of turnout convergence. Regarding income, Choi (2004) found that most states are converging to their regional levels even though only relatively few states are converging to the overall national average. The same may hold true for turnout. The evidence is also strong that the separate regions are converging in income (Loewy and Papell, 1996; Tomljanovich and Vogelsang, 2002). It may, therefore, be worthwhile to investigate if the regions are converging in turnout even if many states individually are not.

\section{REFERENCES}

Ashenfelter, Orley and Stanley Kelly Jr. (1975) "Determinants of Participation in Presidential Elections," Journal of Law and Economics, 18, 695-733.

Burnham, Walter D. (1970) Critical Elections and the Mainsprings of American Politics. W.W. Norton: New York.

\footnotetext{
${ }^{15}$ The test statistic of 0.57 is distributed as $\chi^{2}(3)$ with $p$-value $=0.90$.
} 
Carlino, Gerald A. and Leonard O. Mills. (1993) “Are U.S. Regional Incomes Converging?" Journal of Monetary Economics, 32, 335-346.

. (1996a) "Testing Neoclassical Convergence in Regional Incomes and Earnings," Regional Science and Urban Economics, 26, 565-590.

- (1996b) "Convergence and the U.S. States: A Time-Series Analysis," Journal of Regional Science, 36, 597-616.

Cebula, Richard J. (2004) "Expressiveness and Voting, Alternate Evidence," Atlantic Economic Journal, 32, 215-220.

. (2005) "Strong Presidential Approval or Disapproval Influencing the Expected Benefits of Voting and the Voter Participation Rate," Atlantic Economic Journal, 33, 159-167.

Choi, Chi-Young. (2004) "A Reexamination of Output Convergence in the U.S. States: Toward Which Level(s) are they Converging?” Journal of Regional Science, 44, 713-741.

Converse, Philip E. (1972) "Change in the American Electorate," in Angus Campbell and Philip E. Converse, eds., The Human Meaning of Social Change. Russell Sage Foundation: New York, pp. 263-337.

Crain, Mark W. and Thomas H. Deaton. (1977) "A Note on Political Participation as Consumption Behavior," Public Choice, 32, 131-135.

Dugan, William E. and William A. Taggart. (1995) "The Changing Shape of the American Political Universe Revisited," Journal of Politics, 57, 469-482.

Edwards, George C., III. (2004) Why the Electoral College is Bad for America. Yale University Press: New Haven.

Elliot, Graham, Thomas J. Rothenberg, and James H. Stock. (1996) "Efficient Tests for an Autoregressive Unit Root," Econometrica, 64, 813-836.

Filer, John E., Lawrence W. Kenny, and Rebecca B. Morton. (1991) "Voting Laws, Educational Policies, and Minority Turnout," Journal of Law and Economics, 34, 371-393.

Foster, Carroll B. (1984) "The Performance of Rational Voter Models in Recent Presidential Elections," American Political Science Review, 78, 678-690.

Fuller, Wayne A. (1976) Introduction to Statistical Time-Series. Wiley: New York.

Glaeser, Edward L. and Bryce A. Ward. (2006) "Myths and Realities of American Political Geography," Journal of Economic Perspectives, 20, 119-144.

Green, Donald P. and Lynn Vavreck. (2008) "An Analysis of Cluster Randomized Experiments: A Comparison of Alternative Estimation Approaches," Political Analysis, 16, 138-152.

Haider-Markel, Donald, Melvin Dubnick, Richard Elling, David Niven, and Paul Schumaker. (2002) "The Role of Federalism in Presidential Elections," in Paul D. Schumaker and Burdett A. Loomis, eds., Choosing a President: The Electoral College and Beyond. Chatham House: New York, pp. 53-73.

Kau, James B. and Paul H. Rubin. (1976) "The Electoral College and the Rational Vote," Public Choice, 27, 101-107.

(C) Southern Regional Science Association 2010. 
Kenworthy, Lane. (1999) "Economic Integration and Convergence: A Look at the U.S. States," Social Science Quarterly, 80, 858-869.

Key, Vladimir O., Jr. (1949) Southern Politics in State and Nation. Vintage Books: New York.

Kleppner, Paul. (1982) "Were Women to Blame? Female Suffrage and Voter Turnout," Journal of Interdisciplinary History, 12, 621-643.

Knack, Stephen. (1995) “Does Motor Voter Work? Evidence from State Level Data," Journal of Politics, 57, 796-811.

Longley, Lawrence D. and Neal R. Pierce. (1999) The Electoral College Primer 2000. Yale University Press: New Haven, CT.

Loewy, Michael B. and David H. Papell. (1996) “Are US Regional Incomes Converging? Some Further Evidence," Journal of Monetary Economics, 38, 587-598.

McDonald, Michael P. (2002) "The Turnout Rate among Eligible Voters in the States, 19802000," State Politics and Policy Quarterly, 2, 199-212.

McKee, Seth C. (2008) "Rural Votes and the Polarization of American Presidential Elections," PS: Political Science \& Politics, 41, 101-108.

Mueller, Dennis C. (2003) Public Choice III. Cambridge University Press: Cambridge, U.K.

Perron, Pierre. (1989) "The Great Crash, the Oil Price Shock, and the Unit Root Hypothesis," Econometrica, 57, 1361-1401.

Rusk, Jerrold. (1974) "Comment: The American Electoral Universe: Speculation and Evidence," American Political Science Review, 64, 1220-1238.

. (2001) A Statistical History of the American Electorate. CQ Press: Washington, DC.

Shachar, Ron and Barry Nalebuff. (1999) "Follow the Leader: Theory and Evidence on Political Participation," American Economic Review, 89, 525-547.

Shaffer, Stephen D. (1981) “A Multivariate Explanation of Decreasing Turnout in Presidential Elections, 1960-1976," American Journal of Political Science, 25, 68-95.

Tomljanovich, Marc and Timothy J. Vogelsang. (2002) “Are U.S. Regions Converging? Using New Econometric Methods to Examine Old Issues,” Empirical Economics, 27, 49-62.

Vogelsang, Timothy J. (2001) "Testing for a Shift in Trend when Serial Correlation is of Unknown Form," CAE Working Paper Series 97-11, revised October, 2001.

Wolfinger, Raymond E. and Steven J. Rosenstone. (1980) Who Votes? Yale University Press: New Haven, CT.

Zivot, Eric and Donald W. K. Andrews. (1992) "Further Evidence on the Great Crash, the OilPrice Shock, and the Unit-Root Hypothesis," Journal of Business \& Economic Statistics, $10,251-270$.

(C) Southern Regional Science Association 2010. 